\title{
Certificate in optics and photonics
}

\section{Roger Lessard, Michel Paradis}

Roger A. Lessard, Michel Paradis, "Certificate in optics and photonics," Proc. SPIE 9664, Ninth International Topical Meeting on Education and Training in Optics and Photonics, 96641D (24 October 2005); doi: 10.1117/12.2207759 and Photonics, 2005, Marseille, France 


\title{
Ref ETOP076
}

\section{Certificate in Optics and Photonics}

\author{
Roger A. Lessard and Michel Paradis
}

Department of Physics, Engineering Physics and Optics, Faculty of Sciences and Engineering, Laval University, Quebec City (Quebec) G1K 7P4

Tel: 418-656-2152; Fax: 418-656-2040; E-mail: ralessard@phy.ulaval.ca

\begin{abstract}
This program has been designed for graduate students with bachelor's degrees in engineering or science who possess a sufficiently high level of mathematics training. The Purpose of the program is to prepare those students for work in activity sectors linked to optics, photonics and optical communication. Participants receive theoretical and practical scientific training based principally on physics, physics engineering and optical telecommunications. More specifically, the program enables students to acquire thorough knowledge and skills in electromagnetism, laser, fibre optics, photonics, optical communications and opto-mechanical design. This presentation will describe the program structure, general and specific objectives, courses and learning paths.
\end{abstract}

\section{Key words}

Optics, photonics, optical engineering, training

\section{Summary}

This undergraduate Certificate has been elaborated by Faculty of Sciences and Engineering of Laval University. The Faculty has collaborated with the «Québec-Cité de l'optique» Corporation and the « Ministère des Finances, Économie et Recherche, Mission Industrie et Commerce» Quebec Provincial Government to develop hard skills of Quebec workmanship in optics and photonics domain. Partnership has also been organized with some regional Colleges, the International Institute of Telecommunications (Montréal) and Québec University in Outaouais.

\section{Program structure and procedure}

This is a 30 credit program comprising ten 3-credit courses drawn from among a range of 14 courses. A group of six courses constitutes the initial development block in optics and photonics. This block forms a micro program, and the courses with which it is composed will provide students with solid basic training in the subject.

Two learning paths lead off from this block. The first is a specialization in optics and photonics, while the other constitutes a specialization in optical communications. The development block and selected path together total ten courses and lead to a certificate.

Originally, the program was designated to adults wishing to reorient their careers or to workers in the domain wanting to develop further skills. By now, the different courses will be integrated in the regular undergraduate engineering and science curriculum.

Pedagogical approach has been diversified: andragogy, equilibrium between concepts and practical elements and different applications, case studies, situation scenarios, laboratories, apprenticeship by peers... 


\section{General program objectives}

On completion of the program, the student will:

- Understand the theoretical and practical basis of optics and photonics;

- Be familiar with the technologies related to the various fields of application of optics and photonics;

- Use acquired knowledge to help design and implement systems in the different fields of application of optics and photonics;

- Analyze complex optics and photonics problems using various computer-based tools, particularly simulation software specific to this domain;

- Apply the fundamental concepts related to optics and photonics instrumentation and laboratory techniques.

\section{Special program objectives}

On completion of the program, the student will specifically be able to:

A) Core Curriculum in Optics and photonics Micro Program

1. Explain the basic theoretical and practical concepts related to the field of electrostatic, magneto static and electromagnetism, as well as the mathematical formalism associated with it.

2. Explain the basic theoretical and practical concepts related to the field of geometrical optics through the study of simple optical set-ups and instruments (classical optics).

3. Apply Maxwell's theory of electromagnetism to the domain of wave optics from the following perspectives: emission, propagation and guidance through various medias, wave reception, as well as polarization, interference and scalar diffraction phenomena (classical and wave optics).

4. Apply the theoretical and practical concepts related to optical guidance to concrete problems affecting fibre optic components or systems.

5. Apply the basic concepts related to the operation, characteristics and applications of lasers.

6. Explain the operating principles of optics and photonics devices for emitting, controlling and detecting light and their applications (optoelectronics).

\section{B) Specialization in Optics and Photonics}

7. Solve various problems involving the main phenomena of diffraction optics using Fourier's mathematical formalism (Fourier optics and diffractive optics).

8. Design, integrate and evaluate optical systems taking into account primary theoretical and practical issues (optical design).

9. Apply optical design methods in order to create an operational opto mechanical system which takes into account environmental effects, the mechanical properties of materials and the tolerances imposed by the optical system (opto mechanics).

10. Apply the fundamental concepts of both classical and wave optics using set-ups based on instrumental optics (optics and photonics laboratory).

\section{C) Specialization in Optical Communications}

7. Use theoretical and practical concepts to design optical communications systems and predict their performance.

8. Apply concepts related to networking and optical communication system architecture.

9. Summarize the technological and economic issues relating to the present and future installation of telecommunications systems (the optical telecommunications industry).

10. Apply experimentally the concepts of optical communications and its principal testing and measurement techniques (optical communications laboratory). 